\title{
The Complete Study of the Switch from Iron-Sucrose Originator to Iron- Sucrose Similar and Vice Versa in Hemodialysis Patients
}

\author{
Rottembourg $\mathrm{J}^{1 *}$, Guerin $\mathrm{A}^{2}$, Diaconita $\mathbf{M}^{2}$ and Kadri $\mathrm{A}^{2}$ \\ ${ }^{1}$ Department of Nephrology, Groupe Hospitalier Pitié-Salpêtrière, Paris, France \\ ${ }^{2}$ Diaverum group, Hemodialysis Units, Paris, France
}

\begin{abstract}
Aim: To describe and compare the hematological parameters and anemia medications used in chronic kidney disease (CKD) patients undergoing hemodialysis (HD), before and after switching between the Iron-Sucrose originator (IS), and an Iron-Sucrose Similar (ISS).

Methods: An observational single-center longitudinal study comparing the impact of changing from the original intravenous IS (Venofer $\AA$ ), to an ISS (Fer Mylan $\AA$ ), then back to the original IS. The analysis compares retrospective data from three consecutive 26-week IS treatment periods (P1, P2, and P3), versus a prospective 26-week ISS period (P4), followed by a further 26-week prospective period using the original IS (P5). Hemoglobin (Hb) was assessed every two weeks, while serum ferritin, transferrin saturation (TSAT), and C-reactive protein (CRP) were collected twice per period. ESA (darbepoetin alfa [DA]) was prescribed IV once every two weeks and IV iron was given once weekly, except for P5 where it was administered once every two weeks. Dose titration of ESA and IV iron was per institutional protocol to maintain $\mathrm{Hb}$ between 11.5 and $12 \mathrm{~g} / \mathrm{dL}$.

Results: Sixty-six patients (68\% male) with a mean age of $60 \pm 15$ years were analyzed. Mean $\mathrm{Hb}$ levels remained stable and within the target range during treatment with IS (11.8 $\pm 1.0 \mathrm{~g} / \mathrm{dL})(\mathrm{P} 1$ to $\mathrm{P} 3)$ but decreased significantly after the switch to ISS $(11.3 \pm 0.9 \mathrm{~g} / \mathrm{dL})(\mathrm{P} 4)(\mathrm{p}<0.001)$. Upon switching back to the original IS, $\mathrm{Hb}$ target levels were again attained $(11.8 \pm 0.7 \mathrm{~g} / \mathrm{dL})(\mathrm{P} 5)$. During the P1 to P3 periods, TSAT remained stable $(43.7 \pm 8.5 \%)$ but decreased during the (P4) period $(23.9 \pm 9.5 \%)$ and returned to previous level $(41.5 \pm 10.8 \%)$ with the switch back to IS (P5). Cumulative ESA and IV iron doses were stable during P1 to P3, had to be increased by $27.1 \%$ and $30.3 \%$ respectively during P4, and could again be decreased by $22.5 \%$ and $30.3 \%$ with the return to IS during P5.

Conclusions: The switch from IS to ISS preparation led to destabilization of the previously well-controlled population of HD patients, with a return to stable levels after a switch back to IS. The switch resulted in an increase in total anemia drug treatment costs, with higher iron and ESA doses required with an ISS. Caution should be exercised before substituting IS with ISS in the absence of therapeutic equivalence data.
\end{abstract}

Keywords: Anemia; Cost; Hemodialysis; Interchangeability; Iron sucrose; Iron sucrose similar; Non-biological complex drug (NBCD)

\section{Introduction}

Anemia is a common phenomenon in patients with chronic kidney disease (CKD). Its prevalence, beginning mostly in stage 3-4 of the disease [1], rises as renal function deteriorates, and it is estimated that up to $85 \%$ of the patients are anemic at the time of starting dialysis [2]. Anemia has been suggested as an independent factor for impaired cardiovascular pathology [3], and may be partly corrected by the addition of iron and Erythropoiesis-Stimulating Agents (ESA), as underlined by the KDIGO guidelines [4] and the European Renal Best Practice Position Statement [5].

Iron deficiency is an important contributor to renal anemia, particularly in hemodialysis (HD). The causes may be multifactorial but largely due to chronic blood loss [6], and increased iron demand due to use of ESAs [7]. Accordingly, intravenous (I.V.) iron supplementation is an important component in the therapeutic armamentarium for the management of anemia in HD patients [8]. Iron carbohydrate preparations are one of non-biological complex drugs (NBCD) category of molecules [9]. Such preparations are used to treat iron deficiency anemia and iron deficiency in a variety of chronic clinical conditions [10], either as monotherapy or in combination with ESAs in order to reduce the required doses and mitigate the potential toxicity of ESA therapy. Since labile (commonly called "free") iron is inherently toxic, intravenous (I.V.) iron preparations take the form of iron carbohydrate complexes in which an iron-containing mineral core is surrounded by a carbohydrate ligand for stability [11]. Differences in the size and structure of the core and the carbohydrate shell profoundly influence the pharmacologic and biologic properties of the complex [11].

Iron sucrose (IS), first introduced in 1949 [12], is used widely to treat iron deficiency in a variety of medical conditions and results in prompt iron utilization by erythrocytes [13]. IS contains no dextran or dextran derivatives, so cannot induce dextran-induced anaphylactic reactions [14], and is generally considered to have a good safety profile, as documented in clinical studies and post-marketing analyses [15]. This can be attributed to the stable structure of IS, which consists of a ferric oxyhydroxyde iron core complexed with sucrose in water, with a molecular weight of 34,000-60,000 Da [15]. The degree of stability of iron carbohydrate complexes is critical, since weakly bound iron may dissociate from the complex and catalyze the generation of reactive

*Corresponding author: Jacques Rottembourg, MD, Department of Nephrology, Groupe Hospitalier Pitié-Salpêtrière, 83 Boulevard de l'Hôpital, 75013 Paris, France, E-mail: jacques.rottembourg@wanadoo.fr

Received: October 31, 2015; Accepted: January 10, 2016; Published: January 27,2016

Citation: Rottembourg J, Guerin A, Diaconita M, Kadri A (2016) The Complete Study of the Switch from Iron-Sucrose Originator to Iron-Sucrose Similar and Vice Versa in Hemodialysis Patients. J Kidney 2: 110. doi:10.4172/2472-1220.1000110

Copyright: (c) 2016 Rottembourg J, et al. This is an open-access article distributed under the terms of the Creative Commons Attribution License, which permits unrestricted use, distribution, and reproduction in any medium, provided the original author and source are credited. 
oxygen species. Stability is highly dependent on the manufacturing process [16].

The fact that iron therapy is increasingly being recognized as an important component of treatment for iron deficiency and irondeficiency anaemia in a variety of clinical conditions has led to the development and introduction of new products (ferric carboxymaltose, isomaltoside 1000) and a number of 'iron sucrose similar' (ISS) preparations [17]. ISS have been launched into the market under the assumption that they are identical to the originator IS. Generic drugs represent an important part of the drug armamentarium and the introduction of safe and effective generic formulation is welcome from an economic perspective and, occasionally, from a clinical standpoint if the generic shows a better safety and efficacy profile than the originator. However, replicating the physicochemical identity of IS is challenging and achieving therapeutic interchangeability with the originator is even more difficult. Proof of pharmaceutical equivalence for ISS on the basis of comparable physico-chemical properties, as described in the United States Pharmacopeia (USP) [18], appears insufficient for NBCD drug classes since they cannot be fully characterized from a physico-chemical standpoint. Moreover, bioequivalence is difficult to demonstrate using I.V. preparations, a problem compounded with colloidal solutions such as iron carbohydrate.

Even more alarming is the virtual absence of safety assessments, a cause of potentially serious concern in view of the risk of toxicity and the fragile clinical status of many patients requiring long-term I.V. iron therapy. A recent safety analysis showed the reporting rate of adverse events with ISSs to be nil, which is virtually impossible given the widespread, multinational use of ISS preparations [19], as well as the fact that several studies have demonstrated evidence for increased adverse events with the substitution of an ISS in clinical practice [20-23].

We have previously reported short-term findings from an observational, single-cohort study demonstrating that switch from the originator IS to an ISS preparation led to destabilization of a wellcontrolled population of HD patients in terms of hemoglobin $(\mathrm{Hb})$ levels and iron status [20]. However, a number of factors influence the $\mathrm{Hb}$ levels in chronic kidney disease patients over time, including the modality of dialysis, iron status, co-morbidities and chronic inflammation [24] such that almost all HD patients exhibit endogenous fluctuation in $\mathrm{Hb}$ levels $[25,26]$. We have therefore undertaken a twoyear retrospective analysis to determine whether the $\mathrm{Hb}$ and iron status of the HD patients remained stable over the long term prior to the switch to ISS [27], and for the first time, we reviewed the switch back to IS, decided for medical reasons.

\section{Patients and Methods}

\section{Period of the study}

A long-term observational, non-interventional, single study was undertaken at the Centre Suzanne Levy, Diaverum group, Paris, France. The aim of the study was to compare anemia-related hematological parameters and anemia medication doses and costs in HD patients with iron deficiency anemia before and after conversion from IS to an ISS. The decision to switch initially from IS to an ISS was made on the basis of economics (i.e, the ISS was significantly cheaper in relation to direct costs than the IS). Post observations of the increased iron needs, increased ESA needs and other medical concerns elected to switch back to the original IS. This longitudinal study hence describes the findings over a 30 months period divided into discrete equal periods to minimise bias due to seasonal fluctuations or other institutional practices.
The study compared five equal time periods of 26 weeks. Periods 1 to 3 were dedicated to demonstrate the $\mathrm{Hb}$ stability in an $\mathrm{HD}$ population receiving the original IS over an, 18 months-time ( 3 periods each of 26 weeks). All data in period 1-3 were retrospectively collected.

Period 4 analysed data after the switch to ISS. A small time period prior to data collection of period 4 was excluded as during this period both IS and ISS preparations were simultaneously available in the unit. Period 5, then analysed patients after again switching back to IS. This prospectively observed period was initiated several months after the end of Period 4, to permit conversion of all patients back to IS. Both period 4 and 5 had data prospectively collected with appropriate ethical committee approvals.

During the full period of observation no other changes to medical management or clinical practices were implemented other than an adjustment of the $\mathrm{Hb}$ target level after publication of international recommendations suggesting a lower target $\mathrm{Hb}$ [28].

\section{Iron and Erythropoiesis-stimulating agent administrations}

IS (Venofer', Vifor International, St Gallen, Switzerland; $5 \mathrm{ml}$ ampoules with $100 \mathrm{mg}$ iron) or ISS (Fer Mylan ${ }^{\circledR}$ ISS2, Mylan SAS, Saint Priest, France, manufactured by Help SA Pharmaceuticals, Athens, Greece; $5 \mathrm{ml}$ ampoules with $100 \mathrm{mg}$ iron) were injected I.V. once a week at a dose of 25-100 mg iron, adapted to iron parameters, during periods 1 to 4 . During period 5 after the publication of the synergistic effect of the administration of IV iron and ESA [29] during the same dialysis session, IV iron was injected every two weeks. Both I.V. iron preparations were diluted with saline solution $(0.9 \%)$ up to $20 \mathrm{ml}$ volume and infused over a one-hour period, between the second and the third hour of the dialysis session, in the arterial line before the dialyzer. The I.V. iron dose was titrated according to the most recent values of transferrin saturation (TSAT) and serum ferritin, targeting a TSAT level of $40-60 \%$ and a serum ferritin concentration of 500-800 $\mu \mathrm{g} / \mathrm{l}[30]$.

The ESA darbepoetin (Aranesp; Amgen, Boulogne-Billancourt, France) was injected I.V. once every two weeks and titrated according to the previous $3-4 \mathrm{Hb}$ values and taking into account any surgical or clinical event [31].

The target $\mathrm{Hb}$ range for all patients at the centre was 11.5-12.0 g/dl. Medical management of the patients did not change during the study except for the switch from IS to ISS, and the switch back to IS.

\section{Methods}

The study population comprised all HD patients who had undergone at least 350 dialysis sessions in the unit during the study period and received at least one dose of I.V. iron. Measurement of $\mathrm{Hb}$, serum calcium, serum phosphorus, creatinine and urea (prior to dialysis) were obtained every two weeks. TSAT, serum ferritin, alkaline phosphatase, parathyroid hormone (PTH), 25-OH vitamin $\mathrm{D}$, albumin, urea (before and after HD session), adequacy of dialysis (Kt/V), C-reactive protein (CRP), fibrinogen, liver enzymes (asparamate aminotransferase [AST], alanine aminotransferase [ALT], gamma-glutamyl transpeptidase $[\gamma$ GT] and total bilirubin) were measured every three months.

Routine data collection included demographics, primary cause of end-stage renal disease, number of dialysis sessions, and consumption of I.V. iron and darbepoeitin. All adverse events were reported according to applicable regulations and adverse events resulting in hospitalization were recorded. 


\section{Statistical methods}

Mean values for $\mathrm{Hb}$, TSAT and serum ferritin, and consumption of I.V. iron and darbepoetin, were compared using analysis of variance (ANOVA) (a) across the five treatment periods and (b) during Period 3 (IS) versus Period 4 (ISS), and the switch back during Period 5 (IS). Paired data were also analyzed using the Wilcoxon test for continuous data, and the McNemar test $\left(\mathrm{X}^{2}\right)$ for qualitative data.

The cost analysis took the approach of an anemia drug budget impact for a third-party healthcare provider (French Sickness Funds). The costs of I.V. iron medications and darbepoetin were compared during IS administration and ISS administration. The unit cost of I.V. iron (public price) was $12.98 € /$ ampoule ( $100 \mathrm{mg}$ iron) for IS and $10.20 € /$ ampoule (100 mg iron) for ISS (Fer Mylan ${ }^{\star}$ ). The cost of darbepoetinat the center was $1.638 € / \mu \mathrm{g}$. Recently, drug costs changed to $10.00 € /$ ampoule (100 mg iron) for IS, $8.00 € /$ ampoule ( $100 \mathrm{mg}$ iron) for ISS (Fer Mylan ${ }^{\circ}$ ) and $1.36 € / \mu \mathrm{g}$ for darbepoetin- $\alpha$. As a sensitivity analysis the cost assessments were repeated using the new values.

All statistical analyses except the mixed-effects model used SAS V9.2 software (SAS Software Inc., Cary, NC, USA).

\section{Results}

Sixty-six patients were eligible for inclusion in the analysis, the majority being male $45(68.2 \%)$. The mean age was $60 \pm 15$ years and the mean duration of dialysis at the start of the analysis was $62 \pm 39$ months. The primary causes of end-stage renal failure were diabetes $(\mathrm{n}=22,33.3 \%)$, glomerulonephritis $(\mathrm{n}=15,22.7 \%)$, hypertension $(\mathrm{n}=16$, $24.2 \%)$ and other nephropathies $(n=13,19.7 \%)$. The mean number of dialysis sessions was $73 \pm 9$ sessions per patient in Periods 1, 2, 3, 4 and 5. The mean number of $\mathrm{Hb}$ values recorded per patient was 64.2 (range 52-69), with a total number of $1008,1023,1068,1012$, and 1045 values obtained during Periods 1, 2, 3, 4, and 5 respectively (Figure 1).

Mean $\mathrm{Hb}$ concentration during Periods 1, 2 and 3, (IS administration), was $11.9 \pm 1.0,11.8 \pm 1.0$ and $11.8 \pm 0.9 \mathrm{~g} / \mathrm{dl}$, respectively. This decreased to $11.3 \pm 0.9 \mathrm{~g} / \mathrm{dl}$ during Period 4 (ISS treatment) which was statistically significant $(\mathrm{p}<0.0001$ versus Period 3 [ANOVA]) (Table 1 and Figure 2). The mixed-effects model showed that $\mathrm{Hb}$ remained relatively stable during Periods 1-3, with only minor variations that coincided with introduction of new ESA dosing guidelines at the end of 2007. During the ISS period, the model showed a mean decrease in $\mathrm{Hb}$ values of $0.45 \mathrm{~g} / \mathrm{dl}(95 \% \mathrm{CI}-0.66$ to $-0.24, \mathrm{p}<0.0001)$. After the switch-back to IS (Period 5), the Hb level increased with a return to the values previously observed (Period 1-3) to $11.79 \pm 0.70 \mathrm{~g} / \mathrm{dL}$ (P4 vs. P5, $\mathrm{p}<0.001)$.

Levels of serum ferritin and TSAT were stable during Periods 1-3 (Table 1). During Periods 3 and 4 , the mean concentration of serum ferritin was $618 \pm 308 \mu \mathrm{g} / \mathrm{l}$ and $505 \pm 287 \mu \mathrm{g} / \mathrm{l}$, respectively ( $\mathrm{p}=0.003$ ); mean corresponding values for TSAT were $45 \pm 7 \%$ and $24 \pm 10 \%$ $(p<0.0001)$. After the switch back to IS serum ferritin increased back to the values observed during P1 to P3; more important is the return of TSAT to the values observed before the switch from IS to ISS.

Serum concentrations of phosphorus and calcium varied across the five study periods (Table 1). No significant differences across Periods 1-4 or between Period 3 and Period 4 were observed for PTH, albumin, fibrinogen, $\gamma$-GT, alkaline phosphatase, ALT, AST, leucocytes, platelets, neutrophils or Kt/V. There was a significant increase between P1-P3 to P4 on 2 values, CRP and total bilirubin, indicating both the role of the oxidative stress due to the change from IS to ISS (Table1), and a return to basal values after a switch-back to IS after a six months period on ISS.
The Entire Study Design

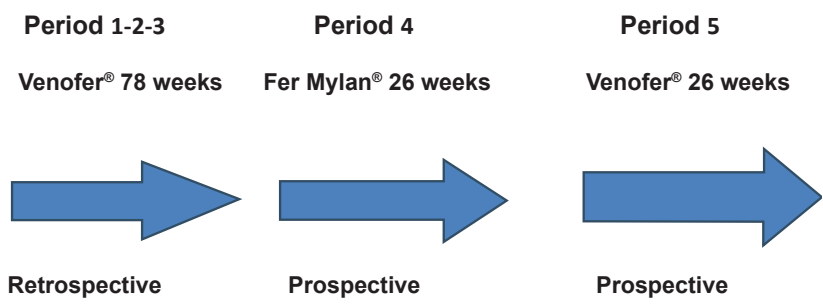

Dec 2008 June 2009 January 2010 August 2010

Figure 1: Design of the entire study: Period 1, 2, and 3 were retrospective in order to point the stability of the main parameters of HD patients under IS. Period 4 was the analysis after the switch from IS to ISS. After a few months, the return to IS was decided and the study was prospective.

I.V. iron therapy was received by all patients during each of the four treatment periods other than seven, four, ten and two patients in Periods 1, 2, 3 and 4, respectively. During Period 5, five patients didn't receive iron therapy. Figure 2 and Table 2 summarize the mean doses of I.V. iron and ESA administered during the five treatment periods. Doses of both therapies were stable during IS treatment, with no significant differences between Periods 1, 2 and 3 (Table 2). Values for mean I.V. iron dose per patient increased significantly from Period 3 (56 $\pm 33 \mathrm{mg} /$ week) to Period 4 (67 $\pm 32 \mathrm{mg} /$ week), an increase of $21.1 \%$ $(\mathrm{p}=0.031)$. In Period 5, with the return to IS a significant decrease in IV iron therapy was observed with values returning to the levels of Period $1-3$ (51 $\pm 28 \mathrm{mg} /$ week $)$.

The mean ESA dose per patient stable from Period 1-3, also increased during Period $4(0.52 \pm 0.50 \mu \mathrm{g} / \mathrm{kg} /$ week to $0.66 \pm 0.56$ $\mu \mathrm{g} / \mathrm{kg} /$ week) by $26.9 \%(\mathrm{p}=0.005)$ (Table 2$)$. On reinitiation of IS, the requirement for ESA returned to the previous levels of $0.52 \pm 0.50 \mu \mathrm{g} /$ $\mathrm{kg} /$ week.

This increase in anemia medication led to a $24.7 \%$ increase in the mean cost of medication per patient per period from Period 3 (1422€) to Period $4(1773 €)$. Using updated prices, the sensitivity analysis showed a similar increase in anemia medication cost from Period 3 to Period 4 (27.3\%), and a similar decrease of $24.5 \%$ with the return to IS, during Period 5.

During the five treatment periods there were no adverse events and no hospitalization considered by the investigators to be related to the study drugs.

\section{Discussion}

Anemia is a common comorbidity in CKD [1] resulting from reduced erythropoietin production by the impaired kidney and iron deficiency secondary to blood loss and uremic status. Virtually all patients on dialysis require iron supplementation, and administration of an effective iron preparation is essential. Given the therapeutic importance of effectively controlling iron-deficiency anemia [32] and the risk of oxidative stress and hypersensitivity reactions [33] the I.V. iron therapy must be selected carefully, particularly since it is typically injected into patients with severe chronic disease over a long term.

Evidence from published clinical studies suggests that ISS preparations may not be equivalent to IS in either effectiveness or safety [20-24]. Our observations also support these findings as the effectiveness of the ISS was inferior to the original IS. In other areas 
Citation: Rottembourg J, Guerin A, Diaconita M, Kadri A (2016) The Complete Study of the Switch from Iron-Sucrose Originator to Iron-Sucrose Similar and Vice Versa in Hemodialysis Patients. J Kidney 2: 110. doi:10.4172/2472-1220.1000110

Page 4 of 6

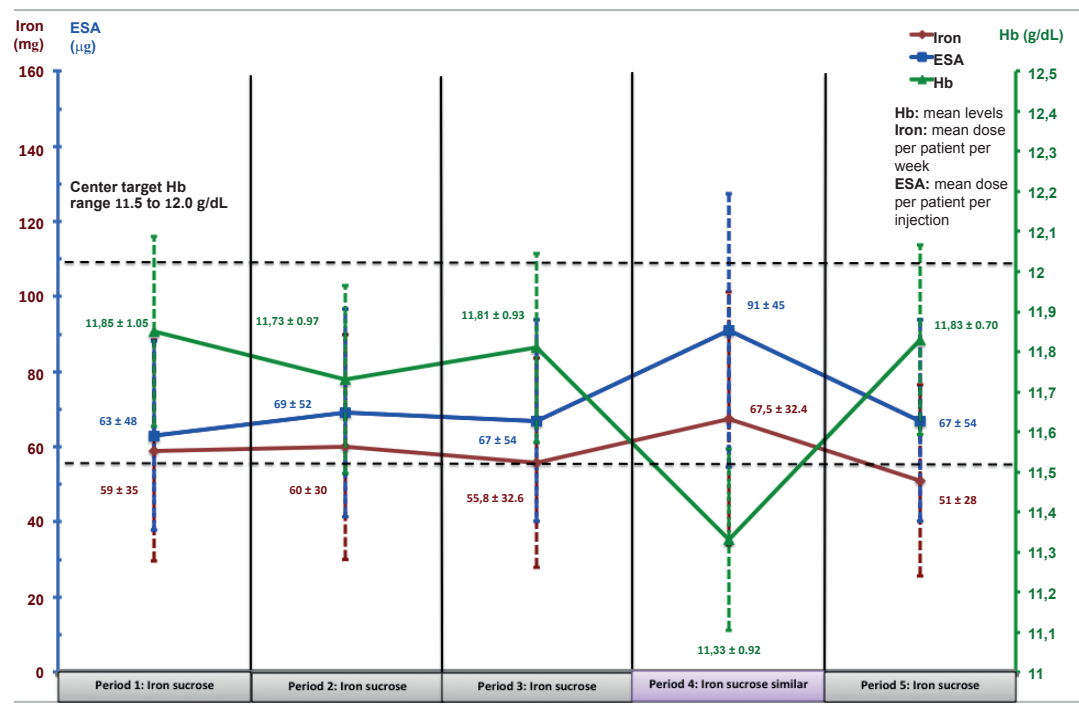

Figure 2: Mean hemoglobin levels as well as IV iron and ESA (erythropoiesis-stimulating agents) before and after the switch from the originator IS to an ISS, and same results after the switch back to IS.

\begin{tabular}{|c|c|c|c|c|c|c|c|c|}
\hline & Period 1 IS) & Period 2 IS) & Period 3 IS) & Period 4 ISS) & Period 5 (IS) & $\begin{array}{l}\text { p value } \\
\text { global }^{\text {a }} \text { ) }\end{array}$ & $\begin{array}{l}\text { p value (Period } \\
1 \text { to } 3 \text { vs. } \\
\text { Period } 4 \text { ) }\end{array}$ & $\begin{array}{l}\text { p value Period } \\
\left.4 \text { vs. Period } 5^{a}\right)\end{array}$ \\
\hline $\mathrm{Hb}(\mathrm{g} / \mathrm{dL})(\mathrm{SD})$ & $11.9(1.0)$ & $11.8(1.0)$ & $11.8(0.9)$ & $11.3(0.9)$ & $11.8(0.7)$ & 0.001 & $<0.001$ & 0.01 \\
\hline Serum ferritin $(\mu \mathrm{g} / \mathrm{L})(\mathrm{SD})$ & $621(420)$ & $644(319)$ & $618(309)$ & $505(287)$ & $649(267)$ & 0.004 & 0.003 & 0.04 \\
\hline TSAT $(\%)(S D)$ & $43(10)$ & $43(9)$ & $45(7)$ & $24(10)$ & $41.5(10.7)$ & $<0.001$ & $<0.001$ & $<0.0001$ \\
\hline Serum phosphorus (mg/dL) (SD) & $5.4(1.7)$ & $5.3(1.5)^{b}$ & $5.5(1.6)$ & $5.2(1.2)$ & $4.9(1.1)$ & 0.086 & 0.019 & 0.05 \\
\hline Serum calcium (mg/dL) (SD) & $8.9(0.6)$ & $8.8(0.6)$ & $9.1(0.6)^{\mathrm{c}}$ & $9.0(0.6)$ & $9.1(0.5)$ & $<0.0001$ & 0.080 & 0.013 \\
\hline C-reactive protein (mg/L) (SD) & $5.4(4.4)$ & $6.7(9.4)$ & $8.7(14.2)$ & $11.6(16.0)$ & $9.44(14.6)$ & 0.080 & 0.05 & 0.06 \\
\hline Albumin (g/L) (SD) & $40.8(3.4)$ & $40.1(3.8)$ & $39.8(4.1)$ & $38.4(4.3)$ & $39.6(4.0)$ & 0.45 & 0.08 & 0.08 \\
\hline Total bilirubin (mmol/L) (SD) & $6.6(2.0)$ & $7.4(1.8)$ & $7.5(2.0)$ & $8.7(2.3)$ & $7.05(2.1)$ & 0.45 & 0.05 & 0.001 \\
\hline LDL-cholesterol (mmol/L) (SD) & $2.0(0.8)$ & $2.1(0.9)$ & $2.0(0.8)$ & $2.1(0.9)$ & $1.9(0.9)$ & 0.45 & 0.37 & 0.06 \\
\hline $\mathrm{Kt} / \mathrm{V}(\mathrm{SD})$ & $1.45(0.19)$ & $1.47(0.23)$ & $1.47(0.25)$ & $1.50(0.25)$ & $1.48(0.23)$ & 0.45 & 0.19 & 0.19 \\
\hline
\end{tabular}

All between-period pair wise comparisons were non-significant unless stated otherwise $\mathrm{Hb}$, hemoglobin; ${ }^{a}$ ANOVA, ${ }^{b} p=0.043$ for period 2 versus 3 , ${ }^{c} p<0.001$ for period 2 versus period 3

Table 1: $\mathrm{Hb}$ levels, iron parameters, and laboratory values in 66 hemodialysis patients during four successive periods of 26 weeks each. Patients received the originator iron sucrose (IS) during Periods 1, 23 and 5, but received ISS during Period 4. Values are shown as mean (SD).

of medicine, concerns have also been expressed about the risks associated with switching to non-originator compounds in the absence of adequate clinical testing $[34,35]$. Because generic and original drugs must demonstrate bioequivalence, one would expect that switching formulations would not be associated with any significant change in everyday clinical practice [36,37].

In this population of stable hemodialysis patients, the switch to an ISS, was associated with a significant reduction in $\mathrm{Hb}$ level and reduced iron indices. This deterioration was observed despite an increase in both I.V. iron and ESA dosing when adopting the ISS into clinical practices. Even if the methodology of injection of iron was slightly different during period 5 , with one injection of iron every two weeks, compared to what was used during period 1 to 4 , due to the publication of the synergistic effect of simultaneous injection of ESA and iron during the same dialysis session [29], the mean dose of iron per week, or the cumulative dose of iron per period, were similar during period 3 and 5; The hemoglobin levels and the ESA doses were also similar during period 3 and 5. On switching back to the original IS, the patients were stabilized and the dosing requirements where subsequently reduced for both the IV iron and the ESAs to levels observed pre-ISS use effectively demonstrating that the issue was indeed related to the ISS and not another external factor.

Variations in complex structure and stability are likely to have accounted for the differences in $\mathrm{Hb}$ control, since the kinetics of iron dissociation influence the pattern of iron release, distribution and storage [16]. In this population of iron-deficient individuals, TSAT values decreased dramatically after the switch, indicating that less iron was available for erythropoiesis. This may signify that iron released from the ISS had been sequestered by other compartments of the body such as the liver, consistent with the more extensive iron deposits observed in liver tissues within the ISS groups of the experimental studies, published by Toblli [38-40].

The increased levels of liver enzymes recorded in the animal model were not mirrored by evidence of hepatotoxicity in our dialysis population, perhaps because doses were far lower in this study, but such an effect cannot be ruled out during long-term ISS therapy in dialysis patients. The increased levels of liver enzymes recorded in the animal models were not mirrored by evidence of hepatotoxicity in the dialysis population because doses were far lower in the clinical 


\begin{tabular}{|c|c|c|c|c|c|c|c|c|}
\hline & Period 1 (IS) & Period 2 (IS) & Period 3 (IS) & Period 4 (ISS) & Period 5 (IS) & $\begin{array}{c}\text { p value } \\
\text { (globala }^{\mid} \text {) }\end{array}$ & $\begin{array}{l}\text { p value (Period } \\
3 \text { vs. } 4^{\mathrm{a}} \text { ) }\end{array}$ & $\begin{array}{l}\text { p value (Period } \\
4 \text { vs. } 5 \text { ) }\end{array}$ \\
\hline \multicolumn{9}{|l|}{ I.V. iron dose per patient, $\mathrm{mg}$} \\
\hline Mean (SD) cumulative dose ${ }^{b}$ & $1149(931)$ & $1193(809)$ & $1077(884)$ & 1405 (901) & $1100(825)$ & 0.099 & 0.031 & 0.03 \\
\hline Median (range) cumulative dose & $1025(0-5200)$ & $1125(0-3800)$ & $1050(0-2800)$ & $1300(0-4150)$ & $1100(0-3200)$ & & - & \\
\hline Mean (SD) per week & $58(35)$ & $60(31)$ & $56(33)$ & $67(32)$ & $51(28)$ & 0.099 & 0.031 & 0.001 \\
\hline \multicolumn{9}{|c|}{ ESA (darbepoetin) dose per patient $(\mu g)$} \\
\hline Mean (SD) cumulative dose & $696(494)$ & $886(666)$ & $872(711)$ & 1109 (857) & $856(750)$ & $<0.001$ & 0.005 & 0.003 \\
\hline Mean dose/kg (SD) per week & $0.39(0.30)$ & $0.50(0.26)$ & $0.52(0.50)$ & $0.66(0.56)$ & $0.52(0.50)$ & $<0.001$ & 0.005 & 0.05 \\
\hline \multicolumn{9}{|c|}{ Cost of anemia medications, $€$ mean (SD) } \\
\hline I.V. iron, total cost & $9839(6064)$ & $10222(6300)$ & $9229(5688)$ & $9455(7416)$ & $9860(6500)$ & & & \\
\hline ESA (darbepoetin) total cost & 67547 (69 155) & 85950 (87 997) & $84628(86643)$ & $107560(110$ 121) & $80250(86480)$ & & & \\
\hline Anemia medications total cost & $77385(75219)$ & $96173(94297)$ & 93857 (92 331) & 117015 (117 537) & $90110(92980)$ & 0.05 & 0.03 & 0.03 \\
\hline
\end{tabular}

Table 2: I.V. iron and ESA (darbepoetin) doses and cost per period in 66 hemodialysis patients during five successive periods of 26 weeks each. Patients received the originator iron sucrose (IS) during Periods 1, 2 and 3, then received ISS during Period 4, and received IS during Period 5. Cost in parenthesis indicate values calculated based on updated prices.

study. It has previously been observed that the administration of I.V. iron carbohydrate complexes with low stability, such as sodium ferric gluconate, can result in severe and extended parenchymal liver necrosis secondary to iron-induced lipid peroxidation in nonclinical models [16] and the high level of total bilirubin and low TSAT seen in the current clinical trial, during period 4 with the use of ISS, are consistent with some degree of hepatic toxicity and less stable molecular structures in the ISS preparations [38]. The significant increase in serum iron and TSAT described in the experimental study from Toblli $[39,40]$, coupled with greater iron deposition, indicated more rapid release of iron compared to IS due to overloading of serum transport proteins. This finding might be attributed to the difference in the kinetics of iron dissociation after changes in the stability of the core of the ironsucrose complex [41]. Slight alterations in the manufacturing process of iron carbohydrates can result in disparities in the structure, molecular weight distribution and stability of the iron-oxyhydroxide core of the iron-sucrose complex [9].

The results of this study might be unable to be generalized to other IV ISS's formulations. Side effects in patient populations have also been observed with other ISS in gastroenterology [21], gynecology [23], and recently partly in nephrology with the changes induced after switching from a generic formulation to an original formulation [42]. Our recommendation is that the selection of a specific iron should not be based solely on financial considerations, between original molecules and their similar, assuming comparable efficacy and safety, because original and similar formulations might not be interchangeable.

The original reason for switching to an ISS was due to the financial aspect - namely that the ISS was cheaper than the IS. This complies with WHO guidelines which promote the use of generic drugs as a strategy to mitigate high pharmaceutical prices [36]. However, in the current analysis, conversion to an ISS resulted in a substantial increase in the total cost of anemia medication $(+27.3 \%)$ The increased overall cost was due to requirement for higher doses of both IV iron $(+30.3 \%)$ and ESA therapy (+27.1\%). As such the cost benefits of the cheaper direct drug costs are negated with the overall cost which then refutes the rationale for a switch based on financial perspectives.

The main limitations of this study are inherent to its design: it is not a randomized double blind cross-over study. Although our different periods with a prolonged period with IS, followed by ISS, and a return to IS allowed us to control for many confounding factors, the data obtained from this observational, single-centre study might not be generalized to all iron formulations and their similars. Main publications were with others similar from iron-sucrose, and a study is currently realized in the United States concerning sodium ferric-gluconate iron complex and its generic formulation [Nulecit FDA-SOL-1120929]. The followup period was adequate for analyzing the effects of the treatment on anemia parameters, but it was not valid for evaluating the long-term outcomes associated with each formulation. Further to above specified potential iron accumulation in tissues such as liver, heart and kidney, high doses of ESAs $[43,44]$ and/or IV iron $[45,46]$ have been linked to increased mortality in HD patients. In this study the use of iron sucrose similar is associated with higher ESA doses and higher IV iron doses, than with the IV iron original formulation. Assuming that the total iron content is indeed correct for the ISS (and equivalent to the IS) then it remains an open question to the final deposition and location of this additional iron with the use of the ISS. Additional randomized controlled studies with longer follow-up periods must be designed to confirm our results.

In conclusion, the treatment of anemia in HD patients with the original IV iron-sucrose formulation permits lower doses of both iron and ESAs for anemia management when compared to an ISS.The original IS was more effective in achieving target iron and $\mathrm{Hb}$ levels with lower individual doses, representing both a cost saving (versus a similar formulation) and perhaps also a long term safety benefit (as unclear where the excess iron from the ISS is deposited). Switching from the original iron sucrose formulation to a similar formulation destabilizes this population and the return to the original formulation of iron-sucrose authorizes the restoration of adequate parameters.

\section{Acknowledgements}

Data were recorded by Hemodial (PHP development).The authors wish to thank Dr Antoine Lafuma for contributing to the statistical analysis of the observational study, and Mireille Griuncelli for her technical assistance for the drawing of the figures.

\section{Disclosure of Financial Competing Interests}

Vifor (International) Ltd and Fresenius Medical Care France financially supported the study and the statistical analysis. The study design was elaborated by Professor Jacques Rottembourg, who received a consultancy fee from Vifor Pharma Ltd following the conclusion of the study.

\section{References}

1. McClellan W, Aronoff SL, Bolton WK, Hood S, Lorber DL, et al. (2004) The prevalence of anemia in patients with chronic kidney disease. Curr Med Res Opin 20: 1501-1510 
Citation: Rottembourg J, Guerin A, Diaconita M, Kadri A (2016) The Complete Study of the Switch from Iron-Sucrose Originator to Iron-Sucrose Similar and Vice Versa in Hemodialysis Patients. J Kidney 2: 110. doi:10.4172/2472-1220.1000110

2. Locatelli F, Del Vecchio L, Pozzoni P (2007) Treating anemia at different stages of renal disease. J Nephrol 20 Suppl 12: S33-38.

3. Finkelstein FO, Story K, Firanek C, Mendelssohn D, Barre P, et al. (2009) Health-related quality of life and hemoglobin levels in chronic kidney disease patients. Clin J Am Soc Nephrol 4: 33-38.

4. (2012) KDIGO Clinical Practice Guideline for Anemia in Chronic Kidney Disease. Kidney Int Suppl; 2: 280-335

5. Locatelli F, Barany P, Covic A, De Francisco A, Del Vecchio L, et al. (2013) Kidney disease: Improving global outcomes guidelines on anaemia management in chronic kidney disease: a European best practice position statement. Nephrol Dial Transplant 28: 1346-1359.

6. Sargent JA, Acchiardo SR (2004) Iron requirements in hemodialysis. Blood Purif 22: 112-123.

7. Macdougall IC (2010) Iron supplementation in the non-dialysis chronic kidney disease (ND-CKD) patient: oral or intravenous? Curr Med Res Opin 26: 473-482.

8. Bailie GR, Larkina M, Goodkin DA, Li Y, Pisoni RL, et al. (2013) Variation in intravenous iron use internationally and over time: the Dialysis Outcomes and Practice Patterns Study (DOPPS). Nephrol Dial Transplant 28: 2570-2579.

9. Schellekens H, Stegemann S, Weinstein V, de Vlieger JS, Flühmann B, et al (2014) How to regulate nonbiological complex drugs (NBCD) and their followon versions: points to consider. AAPS J 16: 15-21.

10. Fishbane S, Pollack S, Feldman HI, Joffe MM (2009) Iron indices in chronic kidney disease in the National Health and Nutritional Examination Survey 1988-2004. Clin J Am Soc Nephrol 4: 57-61.

11. Danielson BG (2004) Structure, chemistry, and pharmacokinetics of intravenous iron agents. J Am Soc Nephrol 15 Suppl 2: S93-98.

12. Paschen HW (1949) Efficient anaemia treatment with large intravenous iron doses. Geburtshilfe Fauenheilkunde 9: 604-616.

13. Beshara S, Lundqvist H, Sundin J, Lubberink M, Tolmachev V, et al. (1999) Pharmacokinetics and red cell utilization of iron(III) hydroxide-sucrose complex in anaemic patients: a study using positron emission tomography. $\mathrm{Br}$ Haematol 104: 296-302.

14. Bailie GR, Clark JA, Lane CE, Lane PL (2005) Hypersensitivity reactions and deaths associated with intravenous iron preparations. Nephrol Dial Transplan 20: $1443-1449$.

15. Yee J, Besarab A (2002) Iron sucrose: the oldest iron therapy becomes new. Am J Kidney Dis 40: 1111-1121.

16. Geisser P, Burckhardt S (2011) The pharmacokinetics and pharmacodynamics of iron preparations. Pharmaceutics 3: 12-33.

17. Toblli JE, Cao G, Angerosa M (2015) Cardiovascular outcomes of intravenous iron in perspective of clinical trials and the use of different iron preparations. Int J Cardiol 187: 196-197.

18. United States Pharmacopeia

19. Bailie GR, Hörl WH, Verhoef J-J (2011) Differences in spontaneously reported hypersensitivity and serious adverse events for intravenous iron preparations: comparison of Europe and North America. Drug Research 61: 265-275.

20. Rottembourg J, Kadri A, Leonard E, Dansaert A, Lafuma A (2011) Do two intravenous iron sucrose preparations have the same efficacy? Nephrol Dial Transplant 26: 3262-3267.

21. Stein J, Chow AK (2012) Clinical case reports raise doubts about the therapeutic equivalence of an iron sucrose similar preparation compared with iron sucrose originator. Curr Med Res Opin 28: 241-243.

22. Martin-Malo A, Merino A, Carracedo J, Alvarez-Lara MA, Ojeda R, et al. (2012) Effects of intravenous iron on mononuclear cells during the haemodialysis session. Nephrol Dial Transplant 27: 2465-2471.

23. Lee ES, Park BR, Kim JS, Choi GY, Lee JJ, et al. (2013) Comparison of adverse event profile of intravenous iron sucrose and iron sucrose similar in postpartum and gynecologic operative patients. Curr Med Res Opin 29: 141-147.

24. Richardson D (2002) Clinical factors influencing sensitivity and response to epoetin. Nephrol Dial Transplant 17 Suppl 1: 53-59.

25. Ebben JP, Gilbertson DT, Foley RN, Collins AJ (2006) Hemoglobin level variability: associations with comorbidity, intercurrent events, and hospitalizations. Clin J Am Soc Nephrol 1: 1205-1210.
26. Fishbane S, Berns JS (2005) Hemoglobin cycling in hemodialysis patients treated with recombinant human erythropoietin. Kidney Int 68: 1337-1343.

27. Rottembourg J, Moglia A, Emery C (2014) Retrospective chart review: disrupted anemia control in hemodialysis patients following the switch to an iron sucrose similar (ISS) after long-term treatment with the originator iron sucrose (IS) GaBI Journal 3: 116-121.

28. KDOQI (2007) KDOQI Clinical Practice Guideline and Clinical Practice Recommendations for anemia in chronic kidney disease: 2007 update of hemoglobin target. Am J Kidney Dis 50: 471-530.

29. Coulon S, Dussiot M, Grapton D, Maciel TT, Wang PH, et al. (2011) Polymeric IgA1 controls erythroblast proliferation and accelerates erythropoiesis recovery in anemia. Nat Med 17: 1456-1465.

30. Gaweda AE, Bhat P, Maglinte GA, Chang CL, Hill J, et al. (2014) TSAT is better predictor than ferritin of hemoglobin response to Epoetin alfa in US dialysis patients. Hemodial Int 18: 38-46.

31. Rottembourg JB, Dansaert A (2011) [Feasibility strategy of darbepoetin alfa administration every other week: 2005-2007 experience in a dialysis unit] Nephrol Ther 7: 549-557

32. Qunibi WY (2010) The efficacy and safety of current intravenous iron preparations for the management of iron-deficiency anaemia: a review. Arzneimittelforschung 60: 399-412.

33. Bailie GR (2008) Breaking new ground in intravenous iron therapy. Eur Haematol Touch Briefings 2: 58-60.

34. Pitt B, Julius S (2011) Easy money? Health cost savings resulting from the switch from a branded drug to a low-cost generic drug in the same class. Int $\mathrm{J}$ Clin Pract 65: 242-244.

35. Johnston A (2010) Challenges of therapeutic substitution of drugs for economic reasons: focus on CVD prevention. Curr Med Res Opin 26: 871-878.

36. Ramsey S (2013) WHO guideline on country pharmaceutical pricing policies. Recommendation 5.5.Promotion of the use of generic medicines. Geneva World Health Organization. NBK258631.

37. Dunne S, Shannon B, Dunne C, Cullen W (2013) A review of the difference and similarities between generic drugs and their originator counterparts, including economic benefits associated with usage of Generic medicines, using Ireland as a case study. BMC Pharmacol Toxicol 14: 1 .

38. Toblli JE, Cao G, Olivieri L, Angerosa M (2010) Comparison of the renal, cardiovascular and hepatic toxicity data of original intravenous iron compounds. Nephrol Dial Transplant 25: 3631-3640.

39. Toblli JE, Cao G, Oliveri L, Angerosa M (2009) Differences between original intravenous iron sucrose and iron sucrose similar preparations. Arzneimittelforschung 59: 176-190.

40. Toblli JE, Cao G, Oliveri L, Angerosa M (2009) Differences between the origina iron sucrose complex Venofer ${ }^{\circledR}$ and the iron sucrose similar Generis $₫$, and potential implications. Port J Nephrol Hypert 23: 53-63.

41. Slotki I, Cabantchik ZI (2015) The Labile Side of Iron Supplementation in CKD. J Am Soc Nephrol 26: 2612-2619.

42. Agüera ML, Martin-Malo A, Alvarez-Lara MA, Garcia-Montemayor VE, Canton P, et al. (2015) Efficiency of Original versus Generic Intravenous Iron Formulations in Patients on Haemodialysis. PLoS One 10: e0135967.

43. Nishio A, ChhatKuliBP, MA JZ, Kalantari K (2013) Higher doses of erythropoietin stimulating agents and hyporesponsiveness to their effects are associated with increased mortality among prevalent hemodialysis patients. Blood Purif 36: 29-36.

44. Koulouridis I, Alfayez M, Trikalinos TA, Balk EM, Jaber BL (2013) Dose of erythropoiesis-stimulating agents and adverse outcomes in CKD: a metaregression analysis. Am J Kidney Dis 61: 44-56.

45. Miskulin DC, Tangri N, Bandeen-Roche K, Zhou J, McDermott A, et al. (2014) Intravenous iron exposure and mortality in patients on hemodialysis. Clin J Am Soc Nephrol 9: 1930-1939.

46. Zitt E, Sturm G, Kronenberg F, Neyer U, Knoll F, et al. (2014) Iron supplementation and mortality in incident dialysis patients: an observational study. PLoS One 9: e114144. 